\title{
Computerized grants project is unveiled
}

\section{Bethesda, Maryland}

THE halls of the National Institutes of Health (NIH) are paved with grant applications. So are the offices. Come deadline day, when 35,000 applications come in at the last minute, the Federal Express trucks are gridlocked in the parking lot unloading funding appeals. By the time NIH finish making 75 copies of each application and distributing them to all the appropriate offices, the agency is buried under more than 2.5 million applications, each about a hundred pages long - over a thousand tonnes of paper.

In the electronic age, this flood of paper is an embarrassing thorn in the side of the NIH and other US science agencies. Years of vague proposals to computerize the process have produced some abortive trials, several committees and plenty of excuses.

But now, a handful of computer evangelists with some hot machines are finally making progress towards the grail of grantmaking: the all-electronic application and review. No paper, no post - nothing but bits and bytes.

Earlier this month, grants officials unveiled their plans for an electronic future at a meeting of the Division of Research Grants advisory board attended by senior NIH staff. Experimental grant software is nearing completion, they said, and will be tested in preliminary trials in early fall at the University of
South Carolina, the University of Washington and another, yet unnamed, university.

In addition, a collaboration with the $\mathrm{Na}$ tional Science Foundation (NSF) is aiming at a common applications form and software that could be used at both science agencies. The two combined receive some 70 per cent of all grant applications to the federal government.

Researchers are making progress towards the grail of grant-making: the all-electronic application and review. No paper, no post - nothing but bits and bytes.

John Mathis is the motive force behind the most ambitious of the NIH projects - one that will eventually not only allow scientists to create and submit their proposals electronically, but will also let NIH computers read and categorize them without human help. Mathis's vision of a computerized grant-making machine is a mix of simple personal-computer software and complex artificial-intelligence $(\mathrm{AI})$ programs.

Known as the EGAD (Electronic Application and Grant) project, the effort is about to show its first face - a software program for distribution to universities that will check applications for completeness and accuracy in real time as a researcher enters the infor- mation.

The software (designed for Macintosh or IBM-compatible computers) will make sure that the numbers add up at the bottom of the financial portion, and that the researcher has not accidentally given something like 'biology department' as his or her last name.

Typing time and labour are just the most obvious of the savings. Mathis hopes that a sophisticated AI program that is still under design will also take over the tedious chore of assigning applications to the appropriate NIH institute and study section, a task that now requires a panel of in-house scientists.

The AI program, known as 'the referral assistant', will scan an application, looking for information that reveals its scientific field and subject. Several techniques for doing this are being considered, including keyword searches and citation analysis, which would use the references cited at the end of the application as a guide to the science within.

At the National Science Foundation, however, progress on an electronic grants package has been tempered by a sobering example of how hard the transition can be.

In 1988, NSF started a project known as EXPRES to produce a program that would allow scientists to create and submit grant data electronically. Two universities, Carnegie Mellon and the University of Michigan, were to develop a standard 'document

\section{Electronic review: mixed messages}

\section{Washington}

SCIENCE agencies may save a lot of papershuffling by receiving grant applications electronically, but the real delay and expense is still the review process after the applications arrive. Both the National Institutes of Health $(\mathrm{NIH})$ and the National Science Foundation (NSF) fly hundreds of researchers to Washington each year to staff panels that review stacks of applications, ranking them in order of scientific interest, The entire review process costs the two agencies some $\$ 80$ million each year, and can take up to nine months to complete.

Both agencies are considering replacing the traditional face-to-face review group with their electronic equivalents. But as a few trial projects have shown, getting scientists to give their full attention to peer review while sitting in their own offices is a challenge that may defeat even computers.

In an experiment conducted last year. NSF submitted 52 applications to electronic peer-review. After the agency mailed the applications by regular post, the panellists submitted their reviews and exchanged comments over internet, a nationwide computer network.

Overall, the experiment was generally a success. NSF found the comments of the 'e-panels' to be more thoughtful and the reviewers more prepared than in similar face-to-face panels. But they also noted that interaction among the panel members ranged from minimal to virtually non-existent.

"There was very little exchange of e-mail," one officer wrote in a NSF report on the project. "In one panel it was because the opinions were unanimous. The other panel was a disaster. I couldn't get them to do much of anything."

Reviewers, of course, liked not having to travel to Washington, DC. (So did NSF. Bringing a scientist to headquarters costs the agency about $\$ 1,000$ per day. $\mathrm{NIH}$ spend more than $\$ 20,000$ for each of their three-day study sections.) Most reviewers also said they could live without the body language and verbal clues of a face-to-face panel. For small (3-4 people) groups with three to six proposals each, the extra time to prepare thoughtful comments and opinions was worth the lost personal interactions, they said.

NSF, which tends to have smaller review groups and to give programme officers more say over funding decisions, may eventually be able to adopt e-mail reviews for the two-thirds of all reviews that are now conducted at least partly with face-to-face groups.

The $\mathrm{NIH}$, on the other hand, depend almost exclusively on their study sections, which usually number about 20 people probably too large for e-mail review. For some special reviews, however, NIH assemble panels of as few as five reviewers. In past experiments, NIH have occasionally convened panels by conference call and - in at least one abortive trial - mail.

The agency found that conference calls appear to work relatively well at a pinch, although they have none of the advantages of face-to-face reviews (the nonverbal communications) or e-mail reviews (the more careful consideration). But getting reviewers to respond by mail turned out to be hopeless. Almost all the comments came in late, and some never came in at all. "We had to throw some reviews out altogether because we didn't get even three responses," says John Mathis, who ran the NIH experiment.

Until researchers learn to type as fast as they can talk, they are likely to resist being handed a stack of grants for electronic review. Although the trend towards increased use of e-mail is clear, for now, most reviewers would rather fly to Washington than write a ream of comments about somebody else's grant.

C.A. 